\title{
Active mid-IR emissions from rare-earth doped tellurite glass ceramics for bio applications
}

\author{
R Morea ${ }^{1}$, T T Fernandez ${ }^{1}$, A Miguel ${ }^{2}$, M Hernandez ${ }^{3}, \mathrm{~J} \mathrm{M} \mathrm{Ulloa}^{4}$, J Fernandez ${ }^{2,5}$, \\ R Balda ${ }^{2,5}$, J Solís ${ }^{1}$ J Gonzalo ${ }^{1}$ \\ 1. Laser Processing Group, Instituto de Optica, CSIC, Serrano 121, E- 28006 Madrid, Spain \\ 2. Dept. of Applied Physics I, Universidad del Pais Vasco UPV/EHU, Alameda Urquijo s/n, E-48013 Bilbao, Spain \\ 3. Instituto de Estructura de la Materia, CSIC, Serrano 121, E- 28006 Madrid, Spain \\ 4. Institute for Systems Based on Optoelectronics and Microtechnology, Universidad Politécnica de Madrid, E-28040 Madrid, Spain \\ 5. Materials Physics Center CSIC-UPV/EHU and Donostia International Physics Center, E-20080 San Sebastian, Spain \\ e-mail address: j.gonzalo@csic.es
}

\begin{abstract}
Intense emission peaking at $2.18 \mu \mathrm{m}$ was successfully obtained from erbium upon carefully designed engineering of its glass host both thermally and spectroscopically. Highly localized crystallization of erbium sites is verified by micro Raman and micro-PL along with TEM characterizations.

OCIS codes: 250.5230 Photoluminescence; (160.5690) Rare-earth-doped materials; 160.2750 amorphous materials
\end{abstract}

Promising bio based applications such as bloodless surgery, non-invasive blood constituents monitoring or high sensitivity tracing of green house gases [1] could be designed starting form optically active materials working within the 2.0-2.3 $\mu \mathrm{m}$ wavelength window. For this purpose, room temperature operated high power devices are entering the market of which rare-earth (RE) doped devices hold a prominent place. But such devices are based today on rare-earth doping of thulium and holmium. Though $\mathrm{Er}^{3+}$ has an active $2.0 \mu \mathrm{m}$ transition to achieve broad emission bandwidth, it is usually quenched in an amorphous matrix and hence rarely reported in glasses or any other amorphous matrices [2]. However, the use of $\mathrm{Er}^{3+}$ as the active ion backbone would leverage efforts and investments done in the telecom industry to non-telecom applications which would allow a quick progression. This work successfully reports the engineering of the base glass matrix to produce the key $2.0 \mu \mathrm{m}$ emission. This was obtained by specific selection of precursors and custom-designed heat treatment of an $\mathrm{Er}^{3+}$ doped fluorotellurite glass.

Glass preparation which is solely based on thermal treatment cycle can affect the transparency of the glass matrix due to strong segregation and delocalized crystallization. But if a perfect balance of nucleation rate and growth of nucleus is ensured and maintained, highly localized but well dispersed nanocrystals are formed without degrading the optical transparency which is an ideal situation for photonic applications. RE fluorides are well known to act as nucleation agents in a glassy matrix. The excess addition of erbium fluoride $\left(\mathrm{ErF}_{3}\right)$ could even induce a scenario to avoid synthesizing a fully amorphous glass phase [3]. Hence the selection of $\mathrm{ErF}_{3}$ as a precursor was one of the key element for the administered crystallization of the amorphous matrix that was chosen to be a fluorotellurite glass with a maximum phonon energy of $\sim 850 \mathrm{~cm}^{-1}$ and a optical transparency up to $\sim 6 \mu \mathrm{m}[4]$.

The precursor fluorotellurite glass $\left(74.6 \mathrm{TeO}_{2}-8.8 \mathrm{ZnO}-16.6 \mathrm{ZnF}_{2} \mathrm{~mol} \%\right.$ doped with $\left.1 \mathrm{wt} \% \mathrm{ErF}_{3}\right)$ was prepared by conventional melt quenching. After quenching, a two step heat treatment was carried out to nucleate a glass-ceramic (GC) phase. The first treatment was done at a temperature close to the glass transition temperature $\left(T_{g} \approx 293^{\circ} \mathrm{C}\right)$ for 10 hours, followed by a 3 hours treatment at a temperature slightly below that of the onset of crystallization. Highly transparent glass ceramic samples were obtained after the heat treatment (figure 1).

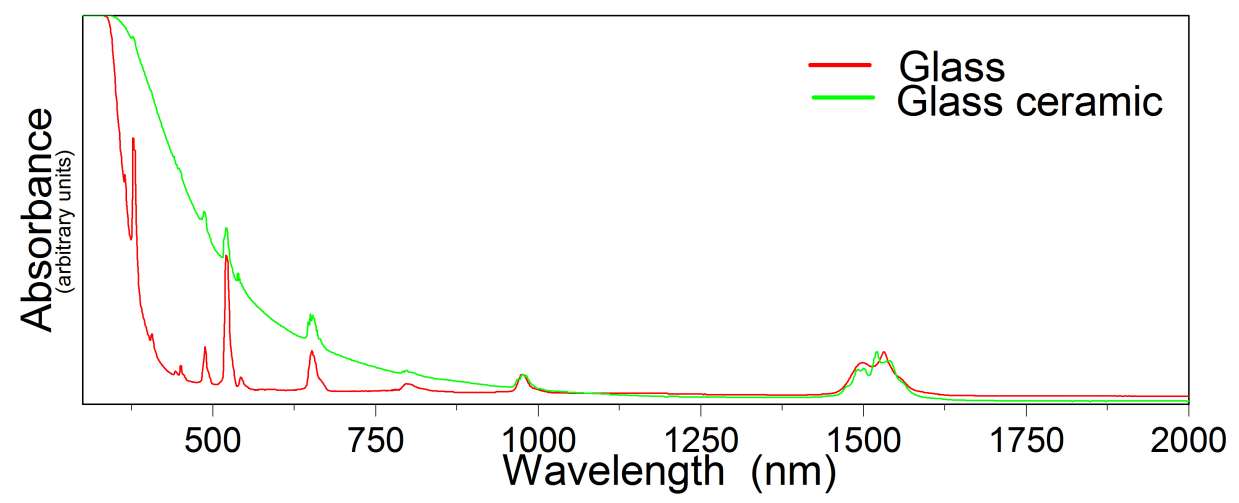

Figure 1 Absorption spectra of glass and glass ceramic sample. 
Micro-Raman analysis was carried out to find microcrystallization due to heterogeneous nucleation that could affect the transparency or induce color-centers which are undesirable for stable photonic devices. Raman spectra were collected in the $250-900 \mathrm{~cm}^{-1}$ spectral region using a confocal Raman microscope (Renishaw inVia) equipped with a He-Cd laser emitting at $\lambda_{\text {exc }}=442 \mathrm{~nm}$ that was focused on the samples using a 50x magnification objective (spectral resolution: $2 \mathrm{~cm}^{-1}$ ). Figure 2a compares the Raman spectra for glass and GC samples indicating almost similar glass network for both except for the subtle shoulders peaking at $\sim 290, \sim 340$ and $\sim 420 \mathrm{~cm}^{-1}$ which can be attributed to the $\mathrm{ErF}_{3}$ nanocrystals present in the GC[5]. Rest all the main band peaks remain unaffected upon crystallization. A 2D mapping of the whole spectra was done over a $20 \times 20 \mu \mathrm{m}^{2}$ area and the main peak shift is plotted in figure $2 \mathrm{~b}$. Results suggest a homogenous crystallization with almost no discontinuities in the glass matrix. The maximum variation obtained was for the symmetric stretch of Te-O bonds in $\mathrm{TeO}_{3+1}$ and $\mathrm{TeO}_{3}$ units $\left(742 \mathrm{~cm}^{-1}\right)$ which was $\pm 3 \mathrm{~cm}^{-1}$ for peak wavenumber and $\pm 5 \mathrm{~cm}^{-1}$ for the FWHM. Figure $2 \mathrm{~b}$ is a representative 2D mapping of peak
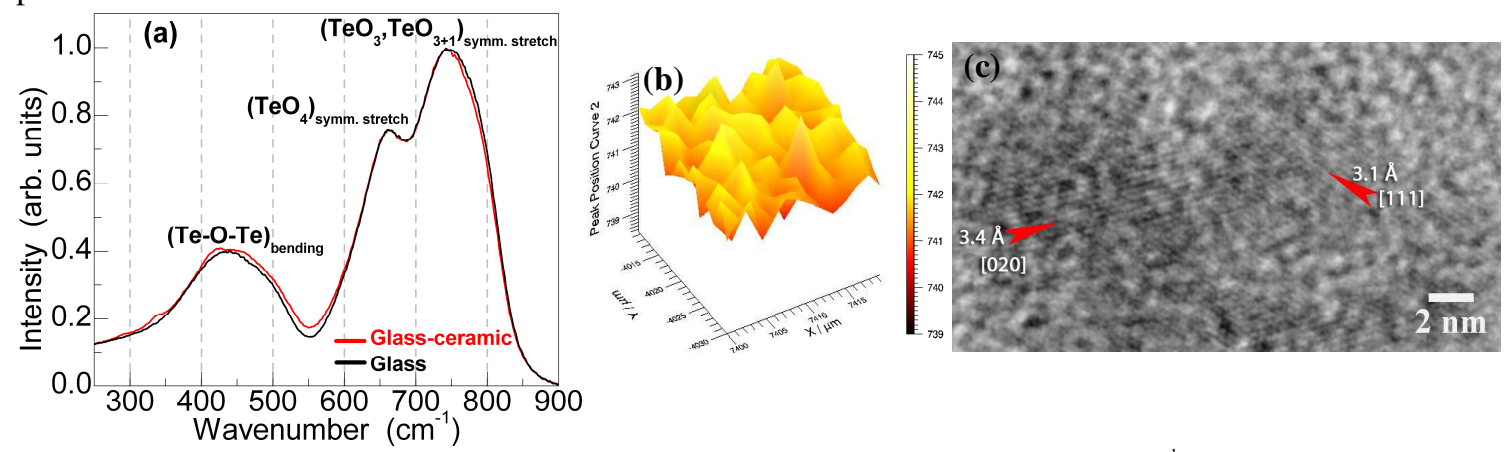

Figure 2 (a) Raman spectra of Glass and Glass ceramic bulk (b) $20 \mu \mathrm{m}$ x $20 \mu \mathrm{m}$ mapping of $742 \mathrm{~cm}^{-1}$ peak shift (c) Lattice planes of $\mathrm{ErF}_{3}$ crystals in TEM marked with their respective orientations and planes.

Micro PL probed the active rare-earth sites of the glass matrix. Strong evidence of site-specific crystallization was obtained. ${ }^{2} \mathrm{H}_{11 / 2}(522 \mathrm{~nm})$ and ${ }^{4} \mathrm{~S}_{3 / 2}(544 \mathrm{~nm}) \mathrm{Er}^{3+}$ transitions to its ground state $\left({ }^{4} \mathrm{I}_{15 / 2}\right)$ [6] were analysed after $980 \mathrm{~nm}$ laser excitation. These hypersensitive transitions are ideal for probing RE environment. ${ }^{2} \mathrm{H}_{11 / 2}$ transition is sensitive to local site symmetry whereas the ${ }^{4} \mathrm{~S}_{3 / 2}$ provides indication about changes in the coordination environment [7]. ${ }^{2} \mathrm{H}_{11 / 2}$ band remained almost unchanged, whereas major changes were observed for the ${ }^{4} \mathrm{~S}_{3 / 2}$ band emission indicating that the local site symmetry is least affected compared to the coordination environment. In the GC spectrum (Fig. 2b) the high energy sub-band splitting of ${ }^{4} S_{3 / 2}$ is quenched and shows more Stark splitting compared to its low energy counterpart. The additional Stark splitting of this level indicates the presence of $\mathrm{Er}^{3+}$ in sites with lower phonon energy. The formation of $\mathrm{ErF}_{3}$ nanocrystals was finally confirmed by TEM (Fig 2c).

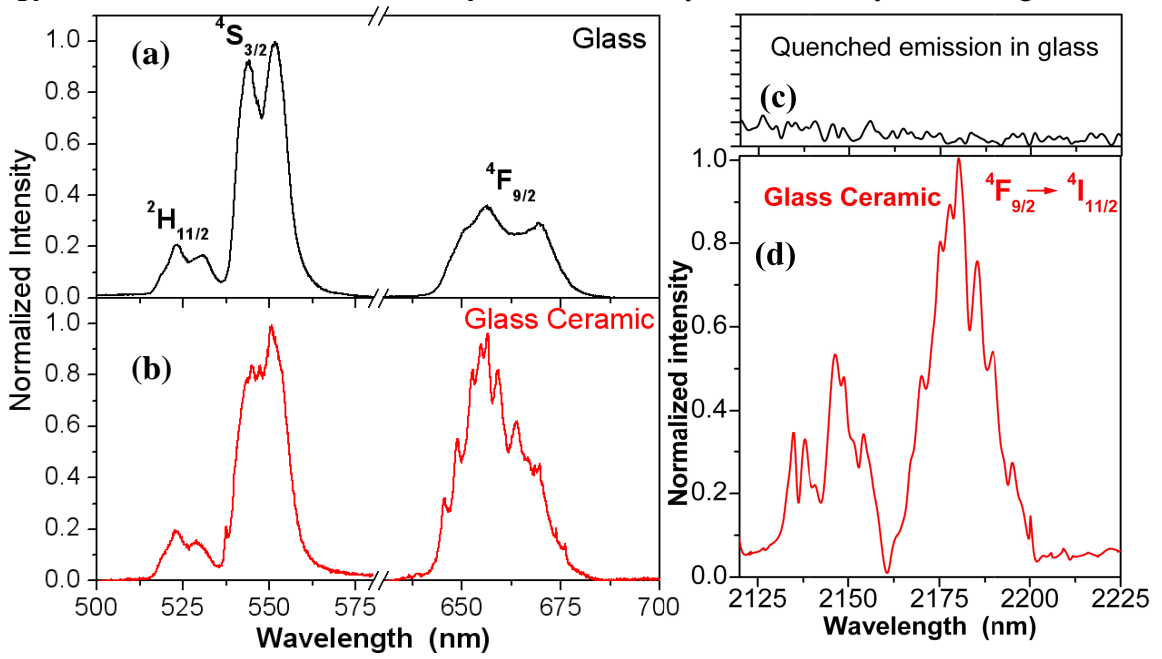

Figure 3. Green and red emissions from (a) Glass (b) Glass ceramic. The Mid-IR emission (c) quenching in glass (d) in Glass ceramic.

The presence of $\mathrm{ErF}_{3}$ nanocrystals has a strong effect in the visible emission of the $\mathrm{Er}^{3+}$ ions. From comparing figure $3 a$ and $3 b$ it is evident that red emission in the $\mathrm{GC}\left({ }^{4} \mathrm{~F}_{9 / 2}\right)$ is dramatically enhanced. We believe this is likely due to the co-operative energy transfer between $\mathrm{Er}^{3+}$ ions because of shorter inter-ionic distances in the crystalline 
environment. The population of ${ }^{4} \mathrm{~F}_{9 / 2}$ level by energy transfer in the GC is in fact the basis of the generation of the $2.0 \mu \mathrm{m}$ emission from the amorphous matrix without leading to fluorescence quenching. ${ }^{4} \mathrm{~F}_{9 / 2} \rightarrow{ }^{4} \mathrm{I}_{11 / 2}$ emission from the GC is shown in figure $3 \mathrm{~d}$ whereas figure $3 \mathrm{c}$ shows the quenching of the same emission in the glass matrix.

The $2.18 \mu \mathrm{m}$ emission from the GC is a potential candidate for high power laser applications and owing to the importance of the wavelength, it could be used to develop photonic devices working in the $2.0-2.3 \mu \mathrm{m}$ wavelength window which has high applicability for biomedical, biochemical, biotechnological applications. In conclusion, we have successfully engineered a $2.18 \mu \mathrm{m}$ emission from an amorphous matrix by site-specific nucleation technique. $\mathrm{Er}^{3+}$ sites were crystallized to form $\mathrm{ErF}_{3}$ nanocrystals, this triggered the population of ${ }^{4} \mathrm{~F}_{9 / 2}$ level leading to intense ${ }^{4} \mathrm{~F}_{9 / 2} \rightarrow{ }^{4} \mathrm{I}_{11 / 2}$ emission peaking at $2.18 \mu \mathrm{m}$.

\section{Acknowledgements}

This work has been supported by the Spanish Ministry of Economy \& Competitiveness (Projects TEC2011-22422, FIS2011-27968 and TEC2012-38901-C02-01) and the Basque Country Government (Project IT-659-13). R. Morea and A. Miguel acknowledge FPI grants from the Spanish Government.

\section{References}

[1] Editorial, "Extending opportunities," Nat Photon, vol. 6, pp. 407-407, 2012.

[2] T. Schweizer, D. Brady, and D. W. Hewak, "Fabrication and spectroscopy of erbium doped gallium lanthanum sulphide glass fibres for mid-infrared laser applications," Optics Express, vol. 1, pp. 102-107, 1997.

[3] M. Mortier and G. Dantelle, "Oxyfluoride Transparent Glass Ceramics," in Functionalized Inorganic Fluorides, ed: John Wiley \& Sons, Ltd, pp. 273-305.

[4] T. T. Fernandez, S. M. Eaton, G. Della Valle, R. M. Vazquez, M. Irannejad, G. Jose, et al., "Femtosecond laser written optical waveguide amplifier in phospho-tellurite glass," Optics Express, vol. 18, pp. 2028920297, 2010.

[5] R. M. A. Miguel, M. A. Arriandiaga, M. Hernandez, F. J. Ferrer, C. Domingo, J. M. Fernandez-Navarro, J. Gonzalo, J. Fernandez, and R. Balda, "Structural, optical, and spectroscopic properties of Er3+-doped TeO2-ZnO-ZnF2 glass-ceramics," Journal of european ceramic society, vol. (In press), 2014.

[6] A. Miguel, R. Morea, J. Gonzalo, M. A. Arriandiaga, J. Fernandez, and R. Balda, "Near-infrared emission and upconversion in Er3+-doped TeO2-ZnO-ZnF2 glasses," Journal of Luminescence, vol. 140, pp. 38-44.

[7] T. Toney Fernandez, P. Haro-González, B. Sotillo, M. Hernandez, D. Jaque, P. Fernandez, et al., "Ion migration assisted inscription of high refractive index contrast waveguides by femtosecond laser pulses in phosphate glass," Optics Letters, vol. 38, pp. 5248-5251, 2013. 